\title{
A CONSTRUÇÃO DO OUTRO PELO OUTRO: A CATEGORIZAÇÃO HIERÁRQUICA DO SUJEITO NA SOCIEDADE DE A LETRA ESCARLATE
}

\author{
Leandro de Azevedo Thereza \\ Universidade Estadual de Ponta Grossa
}

\begin{abstract}
Resumo: Em A Letra Escarlate, romance estadunidense de 1850, Nathaniel Hawthorne nos apresenta uma a sociedade puritana de Boston-Massachusetts, a qual tinha suas estruturas de poder dominada pelo grupo social masculino que, guiado por princípios religiosos, institui na colônia um modelo social rigidamente hierarquizado. A fim de alcançar a salvação comunitária, realizada pela tentativa de instalação de um Visível Reino de Deus na Nova Inglaterra do século XVII, o puritanismo colonial representado na obra se caracteriza como estruturante de uma sociedade opressiva em que o estabelecimento e reconhecimento das diferenças são determinantes para a construção e manutenção desse modelo. Discutiremos neste artigo a maneira como o autoritarismo punia com diferentes modalidades de exclusão qualquer membro que contrariasse os ideais norteadores da salvação comunitária. Procuraremos, ainda, observar aqui a forma pela qual a construção social e cultural dos gêneros, bem como das instituições de controle social são preponderantes para a identificação dessas diferenças, bem como para o estabelecimento das hierarquias sociais mantenedoras daquele modelo.
\end{abstract}

Palavras-Chave: Autoridade. Diferença. Puritanismo. Sexismo. Hierarquia.

\section{Introdução}

O romance estadunidense A Letra Escarlate, de Nathaniel Hawthorne, publicado pela primeira vez em 1850, nos apresenta uma comunidade liderada exclusivamente pelo grupo social masculino, durante uma série de conflitos geradas com o descobrimento de um grande escândalo: Hester Prynne, prendada costureira imigrante de Amsterdã, incorre no pecado/crime de adultério contra a memória do seu marido dado como morto na travessia do

\footnotetext{
${ }^{*}$ Mestrando em Linguagem, Subjetividade e Identidade, da Universidade Estadual de Ponta Grossa - PR, área de Letras, área de concentração: Subjetividade, Texto e Ensino. Tem como principais objetivos de estudos a Língua Inglesa e a Literatura em Língua Inglesa, com ênfase na Literatura Norte Americana do Século XIX
} 
Atlântico, gerando de sua falta uma menina, Pearl. A partir disso, inúmeros conflitos referentes à construção identitária feminina são observados. Naquela colônia, a mulher estava excluída do exercício de posições relevantes nas instituições formadoras de consciência; apesar disso, é visível um quadro de segregação da mulher pelas próprias mulheres da Nova Inglaterra, formatando-se uma subcategoria do feminino em razão da desobediência aos propósitos religiosos da comunidade. Isso nos mostra que a categorização social visível em $A$ Letra Escarlate extrapola a constituição biológica das personagens, ampliando os apontamentos de Woodward (1997, p 10), ao afirmar que "os homens tendem a construir posições-de-sujeito para as mulheres tomando a si próprios como ponto de referência;" na obra, notamos o grupo social feminino também participando dessa construção, tomando não seu corpo, mas o valor cultural e histórico depositado sobre a imagem de mulher e de esposa puritana para determinar a posição-de-sujeito daqueles que, devido a circunstâncias específicas, tornam-se nocivos à congregação.

\section{Autoridade, diferença e identidade}

As construções das posições-de-sujeito, bem como das identidades a partir de disposições históricas e culturais estabelecidas pelo grupo social dominante, evidentemente masculino, fica mais evidente ao observarmos os acontecimentos envolvendo as personagens Hester e sua filha Pearl. Ao cometer o pecado/crime de adultério, Prynne sofreu inúmeras condenações: primeiramente uma pena restritiva de liberdade; depois o padecimento sobre três horas sobre o cadafalso diante da comunidade de Boston; o permanente uso de uma letra "A" bordada sobre as vestes na região dos seios; por fim, a exclusão do convívio social, fixando residência em uma cabana fora dos limites da cidade. Tais penas foram impostas sobre a adúltera em razão de que

\footnotetext{
Aos olhos da Igreja, o adultério era ao mesmo tempo um sacrilégio, um crime contra a ordem natural e um crime contra a ordem social. Pois o casamento unia ao mesmo tempo duas almas fiéis, dois corpos aptos a procriar e duas pessoas jurídicas. Prestava-se a santificar os interesses fundamentais da espécie e os interesses da cidade. Aquele que infringia esse compromisso triplo não era considerado 'interessante', e sim miserável e desprezível (ROUGEMONT, 2003. p 374.)
}

transformando-a em símbolo do desvio para a congregação. A pequena Pearl, embora não tenha cometido pecado algum, exceto nascer, acompanha a mãe em seus martírios desde o início, vindo ao mundo no período em que sua mãe estava encarcerada. Além das punições, percebemos que as personagens passaram a ter um valor simbólico para a comunidade 
puritana, que identificamos como efeito determinante e socialmente estruturante das relações de poder a que estavam sujeitas (COLLIN, 2009, p 61). Isso nos mostra, que "a construção da identidade é tanto simbólica quanto social." (WOODWARD, 1997, p 10) construindo-se a identidade pecadora de Hester e Pearl tal qual "um bricoleurs, que constrói todo tipo de coisas com o material que tem à mão.” (BAUMAN, 2005. p 55) A sociedade puritana tinha em mãos uma pecadora, Hester, e seu pecado, Pearl. A cultura dos opressores era a ferramenta necessária para moldar essa identidade de acordo com as suas necessidades puritanas, agindo essa ferramenta na correção de articulações vistas por eles como falhas ou desviadas na identificação dos puritanos com a identidade para eles edificada. Como vemos,

A identificação é, pois, um processo de articulação, uma suturação, uma
sobredeterminação, e não uma subsunção. Há sempre demasiado ou muito pouco -
uma sobredeterminação ou uma falta, mas nunca um ajuste completo, uma
totalidade. Como todas as práticas de significação, ela está sujeita ao jogo da
différance, ela envolve um trabalho discursivo, o fechamento e a marcação de
fronteiras simbólicas, a produção de efeitos de fronteiras. Para consolidar o
processo, ela requer aquilo que é deixado de fora - e exterior que a constitui.
(HALL, 2009, p 106)

A ferramenta cultural aqui mencionada está relacionada ao papel desempenhado pela figura feminina na Ordem Social Puritana; nesse ordenamento, o homem é responsável pelo provimento espiritual e material da família. A mulher, por sua vez, é o lastro que sustenta os padrões morais da sociedade; essa responsabilidade se deve à crença de uma distinção de poderes e virtudes baseadas no sexo, nominada por Edmund Leites (1986, p. 195.) como "hierarquia recíproca". Explica ainda que "os teólogos puritanos proeminentes do século dezessete não consideravam um sexo como sendo notavelmente mais lascivo que o outro (LEITES, 1986 p. 175.); no entanto os homens eram vistos como mais luxuriosos e as mulheres, mais fracas em seu desejo, estariam menos sujeitas a incorreções de natureza moral. Apesar da menor propensão à incorreções morais, a ausência da virilidade tornava a mulher menos apta às decisões sociais. Como ensina o historiador, essa classificação superior do homem se dá em razão de que

Sua virilidade o torna melhor (à mulher falta essa força animal e vontade de poder) e pior (sua consciência é fraca). A mulher naturalmente ouve a voz moral dentro de si. Sua feminilidade a torna melhor (é eticamente mais pura) e pior (sua pureza depende da falta de força animal e vontade de comandar) (HALL, 2009, p. 196)

Desse modo, a gradação moral da mulher, bem como a subversão dos valores puritanos, influíram incidentemente no julgamento da costureira. Distanciando-se da imagem que a sociedade construiu para a mulher, Hester constituía uma ameaça àquela cultura, pois 
ela constituía um signo de independência da mulher daquela visão de si como um ser capaz de bloquear o reconhecimento do seu próprio desejo sexual. Assim, a comoção popular e, em especial, das autoridades patriarcais estruturantes daquela sociedade não se deu apenas em razão da ofensa à memória do marido, mas também pelo risco de abalar o ícone da perfeição moral (HALL, 2009, p. 199), bem como as próprias estruturas tradicionais puritanas em relação às hierarquias sexuais.

Tal como a Ordem Social Puritana, a Hierarquia Recíproca é um postulado criado no seio de um regime patriarcal; logo, é perceptível a figura do homem construindo a posiçãode-sujeito para a mulher com base na percepção de si. Em torno disso, se constrói então uma identidade feminina cuja respeitabilidade social exigia um comportamento muito mais probo que o do homem, fazendo de seus desvios morais ofensas mais agressivas à sociedade que aquelas cometidas pelos homens, ainda que as ofensas morais fossem de igual ou menor proporção. Por essa razão, as restrições morais a que as mulheres estavam sujeitas eram tanto mais severas quanto, diante de desvios, penalmente mais intensas do que aquelas a que estavam subordinados os homens (HALL, 2009, p. 178), importando em penas mais agudas e humilhantes, como se vê claramente no romance.

O desvio de conduta de Hester Prynne, portanto, incide tanto sobre valores sociais ligados à hierarquia recíproca, atingindo a coletividade de homens e mulheres, quanto sobre valores subjetivos da mulher puritana a respeito de si mesma; a falta da costureira, portanto, feriu valores simbólicos e sociais fortemente agregados à identidade social da colônia. A confissão de Arthur Dimmesdale, clérigo adorado pela comunidade, mas partícipe não revelado do adultério que gerou Pearl, nos traz a resposta para uma questão que nos parece óbvia nesse contexto: fosse a falta de Hester Prynne praticada por um homem, a rigidez da penalidade seria a mesma? A impavidez de alguns somada à atribuição de novos significados simbólicos diante da sua confissão, como a crença de que aquele se constituía um ato santificado de remissão dos pecados através do auto sacrifício, nos basta para compreendermos que a aceitação do homem como mais propenso a desvios morais serve de véu para ocultar uma relativa tolerância à falta masculina. Assim, os conselhos do Reverendo Daniel Rogers (apud LEITES, 1986. p 29), à mulher, dizendo: "Olha pelo teu marido e tuas coisas, deixa que ele seja o véu dos teus olhos, (...) e não olhes adiante" revelam como a "hipocrisia moral puritana" (BAYM, 1986. p. xv) limitava a visão da mulher sobre si e, principalmente, a respeito de si em relação ao homem. 


\section{O casamento como instituição de controle}

Outro aspecto relevante para compreendermos a construção histórica e social da mulher naquela sociedade se vincula ao modelo de casamento puritano. Essa instituição se destacava no seio daquela cultura em razão de que sua organização estabelecida em congregações era alimentada justamente pela harmonia familiar; era dos lares, considerados a origem doméstica da Igreja, que emergia a fé e onde os princípios religiosos deveriam ser estudados e aplicados com maior atenção. O louvor a Deus no interior das casas era outra obrigação a ser seguida, tanto através das leituras sagradas, quanto nas orações e cantos de salmos realizados todas as manhãs por toda a família, tão logo estivesse desperta, e todas as noites antes de dormir, rituais sempre regidos pelo líder familiar (MORGAN, 1966, p. 31). Para assegurar que os princípios cristãos fossem disseminados por todas as famílias da congregação, era comum que alguns homens fossem selecionados na comunidade a fim de inspecionar as famílias com o objetivo de ver se os pais estavam realizando adequadamente os seus deveres religiosos de educação. Percebemos que o zelo pela ação fiscalizadora, no entanto, era aceito pela comunidade, uma vez que constatamos que em 1669, uma votação unânime da Primeira Igreja de Boston decidiu "que os Presbiteros deveriam ir de casa em casa para visitar as famílias e ver quão elas estão instruídas no campo da religião. (MORGAN, 1966, p. 140.) Salientamos que as averiguações eram realizadas por meio de perguntas feitas diretamente às crianças, familiares e servos da casa.

Além dessas formalidades a serem obedecidas no interior das relações matrimoniais e familiares, destacamos que o casamento puritano também era um ato cível subordinado às normas legais impostas pelo Estado. Reproduzindo algumas das regras que sobreviveram à travessia do Atlântico, o casamento era realizado através de um conjunto de cerimônias e contratos entre as partes, semelhante ao que verificamos em modernos contratos pré-nupciais; nesses acordos se observava um conglomerado de cláusulas a respeito das condições em que o casamento se basearia, definições de ordem financeira, administração de bens da esposa por parte do marido, uma vez que segundo as leis de Massachusetts, a partir do momento em que uma mulher contraía matrimônio, todas as suas propriedades passavam à administração do esposo, a fim de que ela pudesse se dedicar exclusivamente à manutenção do lar. Além disso, havia artigos contratuais que vinculavam a consumação do casamento por intermédio da conjunção carnal. 
Nesse momento da discussão, o leitor deve se questionar a respeito da validade do adultério praticado por Hester Prynne, uma vez que ela era considerada viúva. Embora seu esposo, cujo verdadeiro nome não nos é revelado no romance, estivesse dado como morto pela congregação de Boston, a costureira é condenada como adúltera em razão de que o falecimento de uma das partes não garantia à outra parte a possibilidade de um novo casamento ou outras relações de natureza íntima. Naquela cultura, após o casamento, se uma das partes tivesse relações sexuais com outro parceiro, ambos seriam considerados adúlteros, mesmo que um dos envolvidos não fosse casado; e no caso de Hester, ela ainda era considerada casada. Nem mesmo o divórcio era uma garantia do direito a um novo casamento para qualquer uma das partes, sendo bastante restritas as possibilidades de um novo matrimônio. Raramente o divórcio era concedido naquela sociedade colonial; "os motivos pra o divórcio, como revelavam as afirmações dos ministros, eram o adultério, a deserção e abstinência sexual e a ausência do lar por um período de tempo a ser determinado pelo governo civil.” (MORGAN, 1966, p. 36.) Além desses casos, somente o desrespeito aos deveres sagrados do matrimônio eram capazes de permitir o divórcio, sendo esses deveres a coabitação pacífica, união sexual e fiel e suporte econômico da esposa por parte do marido (MORGAN, 1966, p. 42), sendo nesses casos concedido, pois, o divórcio e o direito de um novo casamento (MORGAN, 1966, p. 34).

Em relação à ausência do lar, percebemos que algumas condições normatizavam essa particular condição de divórcio. Primeiramente, de acordo com a colônia em que vivia o casal, havia um lapso temporal a ser transcorrido até que se configurasse a ausência. Em algumas colônias o limite de tempo era de três anos, em outras o prazo era de sete anos, casos nos quais um parceiro era considerado legalmente morto para o outro (MORGAN, 1966, p. 42). No caso especial da colônia puritana de Massachusetts, bem como no caso prático de Hester Prynne, se um marido ou uma mulher lá passasse a residir deixando seu parceiro em sua antiga morada a fim de organizar a casa, ou se aquele se demorasse em função de negócios pendentes, não havia condições de se conseguir o divórcio, a menos que fosse cumprido o prazo estipulado pelo governo (MORGAN, 1966, p. 39). Apesar de as lideranças patriarcais estruturantes da sociedade puritana considerarem erroneamente a morte do esposo de Hester Prynne, que reaparece em sua vida no momento em que a pecadora era exposta à humilhação pública, a punição imposta pelos puritanos visou a proteção da família e do casamento, instituições essenciais à manutenção do discurso patriarcal dominante na colônia, que considerava o corpo familiar como "a fundação de todas as sociedades" (MORGAN, 
1966, p. 39) Nessa fundação, contudo, a figura masculina é significativamente mais importante que a feminina, não somente no desempenho dos papéis de marido e esposa na relação conjugal, mas também como pai e mãe no plano familiar. Embora não haja gradação de autoridade no que se refere ao pátrio-poder, bem como à responsabilidade sobre a educação dos filhos, os modelos familiares e matrimoniais na colônia agem como outro elemento estruturante e determinante para a formatação da identidade feminina. Como afirma Kergoat,

As formas sociais 'casal' ou 'família' (...) são ao mesmo tempo expressão das relações sociais de sexo configuradas por um sistema patriarcal e também espaços de interação social que vão, eles mesmos, recriar o social e dinamizar parcialmente o processo de sexuação social. (KERGOAT, 2009, p. 72)

Dessa forma, o casamento para as mulheres sujeitas àquele regime patriarcal importava na desistência relativa da subjetividade. Essa desistência, por sua vez, é fruto da citada sexuação social imposta às mulheres, o que nos permite apontar que o casamento puritano, ao anular parcialmente a subjetividade feminina, transferia a vida da mulher do espaço privado para um espaço público que se estendia da vida em comum na sociedade às relações maritais. O comportamento dessa mulher deveria obedecer aos princípios ditados pelo controle patriarcal. Inúmeros são os exemplos cabíveis sobre como os discursos religiosos regiam a vida do casal e os caminhos a serem seguidos na vida conjugal. Considerando o caráter Teocrático daquela sociedade, entendemos os sermões como regulamentações estatais, legislações construídas semanalmente durante os cultos religiosos e diariamente nos catecismos familiares professados pelo cabeça da família. Obviamente, o cabeça da família era o marido, sendo a esposa o corpo que seguia seus ordenamentos; Como aponta Edmund Morgan (MORGAN, 1966, p. 45), o papel do homem para a mulher e "para o resto da família ele era 'o canalizador de toda variedade de bênçãos com que Deus os nutria", cabendo à mulher viver em razão do marido, seu fim imediato, e alcançando a Deus, seu fim último, através dele. (MORGAN, 1966, p. 45)

Ao passo que a posição da mulher puritana era inferior aos homens nessa Ordem Social, sendo superior apenas às crianças, Hester e Pearl eram hierarquicamente inferiores às outras mulheres e crianças. Em uma comparação de proporcionalidade, elas estavam para a sociedade colonial assim como a mulher santificada estava para o homem santificado; Hester e Pearl eram “um Mal necessário para que eles fossem um Bem necessário”. Embora as palavras do Reverendo John Cotton apontem para a relação entre homens e mulheres, ao se 
revestirem da identidade do pecado, mãe e filha se tornaram o Mal que a identidade puritana necessitava para se afirmar como o Bem necessário àquele “Visível Reino de Deus".

Cremos que a atribuição da identidade de pecadora a Hester, e também a Pearl, embora não tenha cometido pecado algum, exceto nascer, se relacionam diretamente à construção de um discurso patriarcal puritano sexualmente desfavorável à mulher. O campo social puritano operava a partir de marcações categorizantes, dentre as quais a letra "A" carregada pela costureira participa de maneira simbólica nesse processo classificatório. Como aponta Woodward (2009, p. 14), “o social e o simbólico referem-se a dois processos diferentes, mas cada um deles é necessário para a construção e a manutenção das identidades. A marcação simbólica é o meio pelo qual damos sentido a práticas e a relações sociais." Dessa maneira, a partir da condenação ao uso da letra, Hester Prynne passou a estabelecer uma nova dinâmica às práticas e às relações sociais na Nova Inglaterra, pois o ferrete passa a ser o principal elemento de identificação daquela mulher na comunidade, não sendo reconhecida sequer por sua filha ao retirar o símbolo.

Essa marcação simbólica também é observável em relação a Pearl. Após a humilhação sofrida por Hester perante o público de Boston, a costureira aplicou seus dotes com a agulha de modo a fazer da filha uma verdadeira representação da letra que carregava sobre o peito. Assim, a menina passa a ser a expressão viva daquela marca identitária puritana. Mesmo a maneira pela qual ela passa a ser reconhecida no seio da comunidade aproxima a letra e a menina, pois, no campo discursivo puritano, a letra " $\mathrm{A}$ " era inicialmente considerada o símbolo da infâmia, a marca do desvio e da condenação; Pearl, por sua vez, é inúmeras vezes mencionada como causa e consequência do pecado, ou fruto da vergonha de sua mãe. Pearl é, portanto, o corpo do pecado, e é o corpo "um dos locais envolvidos no estabelecimento das fronteiras que definem quem nós somos, servindo de fundamento para a identidade - por exemplo, para a identidade sexual" (WOODWARD, 2009. p. 15). Como veremos mais detalhadamente adiante, a identidade feminina é significativamente simbolizada pela letra escarlate e também pela menina esquisita. Se as mulheres fazem parte do jogo de significações responsáveis por construir uma identidade puritana masculina partilhada (WOODWARD, 2009, p. 11), mãe e filha passam a reconfigurar as noções de identidade a partir do momento em que se diferenciam das demais mulheres da colônia; isso em razão de que a construção identitária masculina encontrava naquele momento um novo modelo, esse independente dos fatores biologizantes estruturantes daquela cultura. 
Inicialmente em razão da ausência do marido, posteriormente como consequência do banimento, Hester Prynne reuniu condições para se reconhecer independentemente de uma figura masculina a que devesse subordinação. Assim, mãe e filha estão sujeitas a um sistema de produção dos significados sociais completamente novo para elas, bem como para a colônia. Naquela situação, as personagens se encontram em dois mundos diferentes, nos quais desempenham diferentemente suas posições de sujeito na sociedade, pois, claramente, não somente o grupo social masculino, mas também o feminino, observava na pecadora a verdadeira identidade do pecado, enquanto na sua cabana elas estavam livres para se construir como sujeitos de acordo com critérios alheios ao puritanismo, significando uma para outra uma parte igual daquela pequena sociedade da qual faziam parte. Como ensina Woodward, (2009, p. 17) “é por meio dos significados produzidos pelas representações que damos sentido à nossa experiência e àquilo que somos;" ambas representavam o pecado para a sociedade puritana de Boston. O sistema de significação ativo, entretanto, era outro quando as personagens estavam fora do perímetro da cidade; apesar da clara distinção dos papéis desempenhados por Hester, o de mãe e responsável pelo provimento do lar, as personagens representavam entre si um elemento igual naquela pequena sociedade, não havendo qualquer relação hierárquica entre ambas. Dessa forma, o quem somos no isolamento da cabana, local em que passavam a maior parte do tempo, é definido por elas sem a interferência de um discurso patriarcal totalizante.

Já no interior da cidade, a representação de Hester e Pearl como a perdição daquela sociedade entra em conflito com os papéis sociais por ela admitidos; a benevolência de Hester para com os necessitados, como também sua inigualável habilidade com a agulha a transformam em uma personalidade tão necessária à comunidade que, ao longo do tempo, os significados atribuídos à letra e à pecadora foram sendo transformados. Esse conflito nos indica que as transformações dos significados, e também da identidade de Hester para os puritanos se deu em razão de que o pecado era parte necessária a construção daquela cultura.; para o patriarcado da Nova Inglaterra, a nação puritana deveria ter sua identidade fixada dentro de uma unidade ditada por parâmetros morais rígidos sexualmente discriminados, bem como através de uma religiosidade intolerante. Somente a partir do banimento de mãe e filha, e da marcação identitária, primeiramente depositada sobre Hester Prynne, posteriormente reproduzida em Pearl, é que a própria sociedade foi capaz de reconhecer a existência do indivíduo. Aquelas experiências não hierarquizadas vividas fora dos limites da cidade eram, consequentemente, carregadas por elas para o interior da congregação, levando a comunidade 
a reconhecer, mesmo que contra a vontade dos líderes masculinos, dois seres não hierarquizados levando uma vida autodeterminada, que para horror das lideranças daquela sociedade masculinizada, eram mulheres.

\section{Conclusão}

A partir dos conflitos vividos por Hester Prynne em companhia de sua filha Pearl, mesmo que ainda durante a vida intra-uterina, nos mostra um quadro social opressivo em que as inúmeras instituições sociais se demonstravam alheias à existência da mulher como um ser portador de subjetividades. Ao contrário do que se observa no comportamento das personagens femininas aqui destacadas, as demais mulheres de A Letra Escarlate não apenas se desconhecem como sujeito em razão da construção cultural a que estavam submetidas, tanto na educação formal, quanto na informal, dentro de seus lares, mas também reproduzem esse sistema responsável pelo apagamento subjetivo feminino.

Percebe-se que, ao cometer o pecado/crime adultério, Hester Prynne colocou em evidência um modelo conjugal já falido, no qual a preponderância do homem se assemelha à própria figura divina dentro do lar. Os resultados da falta cometida pela costureira retiram a personagem de uma posição-de-sujeito anteriormente enquadrada nos moldes sociais da mulher puritana. Excluída do convívio comunitário, Hester Prynne deixou de ser visualizada como mulher pela sociedade em que vivia, vestindo-se de uma roupagem simbólica de condenação que era considerada desprezível por todos. Esse movimento, entretanto, lhe proporcionou a liberdade necessária para, livre das amarras do casamento, constituir-se como sujeito independentemente dos modelos históricos e culturais que formatavam as mulheres da Nova Inglaterra desde a mais tenra idade.

Dessa forma, entendemos que as estruturas hierárquicas sobre as quais estavam edificados os valores morais puritanos não eram opressivos à mulher somente em razão delas constituírem um grupo social inferiorizado. As exclusões sofridas por Hester e Pearl nos mostram que o grupo social feminino puritano também era capaz de construir posições de sujeito inferiores ao que era considerado moralmente aceito pela sociedade, garantindo, em razão da obediência aos valores que as oprimiam, o direito de oprimir aqueles que não eram interessantes ao Visível Reino de Deus.

\section{Referências}


BAYM, Nina. The Scarlet Letter: A Reading. Boston: Twayne Publishers, 1986.

BAUMAN, Zygmunt. Identidade: entrevista a Benedetto Vecchi. Rio de Janeiro: Jorge Zahar, 2005.

COLLIN Françoise. Diferença dos Sexos (Teoria da), in Hirata, Helena. Dicionário Crítico do Feminismo. São Paulo: UNESP, 2009.

HALL, Stuart. Quem Precisa de Identidade?, in SILVA, Tomaz Tadeu da. Identidade e Diferença: a perspectiva dos estudos culturais. Petrópolis: Vozes, 2009.

HAWTHORNE, Nathaniel. A Letra Escarlate. Tradução: Sodré Viana. 240 p. São Paulo: Martin Claret, 2006. Título Original: The Scarlet Letter. 1850.

HIRATA, Helena et al. (Orgs.) Dicionário Crítico do Feminismo. São Paulo: UNESP, 2009.

KERGOAT, Danièle, Divisão sexual do trabalho e relações sociais de sexo, in HIRATA, Helena et al (Orgs). Dicionário Crítico do Feminismo. São Paulo: UNESP, 2009.

LEITES, Edmund. A consciência Puritana e a Sexualidade Moderna. Tradução: Elide Valarini. Brasília: Brasiliense, 1987. Título Original: The Puritan Conscience and Modern Sexuality, 1986.

MORGAN, Edmund Sears. The Puritan Family. New York: Harper \& Row Publishers, 1966.

ROUGEMONT, Denis de. História do Amor no Ocidente. Tradução: Paulo Brandi. $2^{\mathrm{a}}$ Ed. São Paulo: Ediouro, 2003. Título original: L'amour et l'Occident, 1906.

SILVA, Tomaz Tadeu da. A produção social da identidade e da diferença. in SILVA, Tomaz Tadeu da (Org.). Identidade e Diferença: a perspectiva dos estudos culturais. Petrópolis: Vozes, 2009.

WOODWARD, Kathryn. Identidade e diferença: uma introdução teórica e conceitual, in SILVA, Tomaz Tadeu da (Org.). Identidade e Diferença: a perspectiva dos estudos culturais. Petrópolis: Vozes, 2009.

[Recebido em agosto de 2012 e aceito para publicação em dezembro de 2012]

The construction of the other by the other: the hierarchy categorization of the individual in the scarlet letter's society

Abstract: In The Scarlet Letter, an American novel written in 1850, Nathaniel Hawthorne show us the Puritan society of Boston-Massachusetts, which had its power structures dominated by the male social group that, ruled by religious principles, set up a strict social model totally based on hierarchy. In order to reach the community salvation trough the foundation of a Visible Kingdom of God at New England Colony on $17^{\text {th }}$ century, the colonial Puritanism represented at the novel is seen as the ruler of a oppressive society in which the establishment and recognition of the differences are determinant to the construction and maintenance of that model. The main discussion of this article is the way used by colonial 
authority to punish with different levels of exclusion every member whose behavior was different than the main social ideal: community salvation. Other point here is to observe the construction of social and cultural gender, how institutions involved on social control are relevant to identify those differences and maintenance of the social hierarchy, main support of that social model.

Keywords: Authority. Difference. Puritanism. Sexism. Hierarchy.

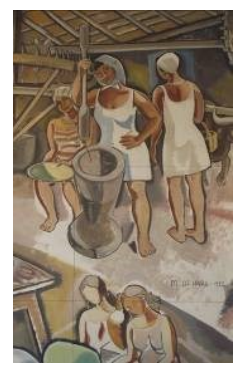

